\title{
Büyüme Korkusu İle Psikolojik Belirtiler Arasındaki İlişkinin İncelenmesi
}

\author{
Nida ATEȘ ${ }^{1}$ ve Melis Seray ÖZDEN-YILDIRIM ${ }^{2}$
}

Öz

Bu çalışmanın amacı büyüme korkusu ile psikolojik belirtiler arasındaki ilişkiyi incelemektir. Bu amaç doğrultusunda büyüme korkusu kavramı, bağımsız yaşama hazırlık ve sorumluluğu içselleştirmede zorlanma, evlenmeye karşı olumsuz tutum, sosyal-duygusal yalnızlık, romantik ilişkiyi sürdürmede zorlanma alt boyutları ile ele alınmıştır. Çalışma, 18-35 yaş aralığında bulunan, İstanbul'da yaşayan, 201 kadın ve 199 erkek olmak üzere toplam 400 kişiyle gerçekleştirilmiştir. Veri toplama aracı olarak Demografik Bilgi Formu, Kısa Semptom Envanteri ve Büyüme Korkusu Ölçeği kullanılmıştır. Çalışma sonucunda büyüme korkusu ile psikolojik belirtilerden hostilite, somatizasyon, olumsuz benlik ve depresyon arasında pozitif yönde anlamlı ilişki bulunmuştur. Büyüme korkusunun bağımsız yaşama hazırlık ve sorumluluğu içselleştirmede zorlanma, romantik ilişkiyi sürdürmede zorlanma ve sosyal duygusal yalnızlık alt boyutları ile hostilite, somatizasyon, olumsuz benlikle ilgili belirtileri ve depresyon arasında pozitif yönde anlamlı ilişki bulunmuştur. Büyüme korkusunun evliliğe karşı olumsuz tutum alt boyutu ile ise sadece anksiyete ve depresyon pozitif yönde anlamlı ilişkilidir. Büyüme korkusunu da sadece anksiyete ve depresyon yordamaktadır. Kadınlar ve erkekler arasında hem büyüme korkusu hem de psikolojik belirtiler açısından istatistiksel olarak anlamlı farklılık bulunmamıştır. Katılımcıların çalışıp çalışmama durumuna göre psikolojik belirtileri incelendiği zaman sadece olumsuz benlikle ilgili belirtileri açısından aralarında anlamlı farklılık olduğu saptanmıştır.

Anabtar Kelimeler: Büyüme Korkusu, Psikolojik Belirtiler, Yetişkinlik

The Investigation of the Relationship between Growth Fear and Psychological Symptoms

\begin{abstract}
The aim of this study is to investigate the relationship between fear growth and psychological symptoms. In the line with this purpose the concept of fear growth was taken with its sub-dimensions; preparation for independent life and difficulty in internalizing responsibility, negative attitude towards marriage, social-emotional loneliness, difficulty in maintaining romantic relationship. The study was carried out with a total of 400 people, aged between 18-35, living in Istanbul, 201 women and 199 men. Demographic Information Form, Short Symptom Inventory and Fear of Growth Scale were used as data collection tools. The results of the study showed that there was a positive significant relationship between growth fear and hostility, somatization, negative self, depression and general symptomatic index. It was found that there was a positive correlation between the dimensions of fear of growth, difficulty in internalizing preparedness and responsibility for independent living, difficulty in maintaining romantic relationships, and social emotional loneliness, and symptoms related to hostility, somatization, negative self-efficacy, and depression. On the other hand, anxiety and depression are positively and positively correlated with the negative attitude towards growth. Anxiety and depression predict fear of growth. There was no statistically significant difference between women and men in terms of fear of growth and psychological symptoms. When the psychological symptoms of the participants were examined according to whether they were working or not, there was a significant difference between them only in terms of negative self-related symptoms.
\end{abstract}

Key Words: Growth Fear, Psychological Symptoms, Adulthood

\section{Atıf İçin / Please Cite As:}

Ateş, N. ve Özden-Yıldırım, M. S. (2020). Büyüme korkusu ile psikolojik belirtiler arasındaki ilişkinin incelenmesi. Manas Sosyal Araștirmalar Dergisi, 9(1), 402-410.

\footnotetext{
${ }^{1}$ Arş. Gör. - İstanbul Arel Üniversitesi Sosyal Bilimler Enstitüsü Klinik Psikoloji Doktora Öğrencisi, nidaates@yahoo.com ORCID: 0000-0002-5584-7378

2 Dr. Öğr. Üyesi - İstanbul Kültür Üniversitesi Fen Edebiyat Fakültesi Psikoloji Bölümü, m.ozden@iku.edu.tr ORCID: 0000-0003-2829-9481
} 


\section{Giriş}

Son yllarda genç yetişkin olarak tanımlanan 18-25 yaş arası grupta yer alan kişilerin yetişkinlik döneminde kendilerinden beklenen birçok sorumluluğu taşımaktan kaçındıkları gözlenmektedir. Bu kişiler, ergenlik dönemini tamamlamış olmakla beraber kendilerini henüz yetişkin olarak tanımlamamaktadırlar. Arnett'in (2004) "beliren yetişkinlik" olarak tanımladığı bu dönem aslında kişilerin yetenek ve sınırlarını keşfetmeye çalışıkları bir kimlik arayışı dönemi olarak da tanımlanabilir. Bu kimlik arayışı dönemi yetişkinlik öncesi bir hazırlık dönemi gibidir, fakat özellikle son yıllarda bazı kişiler için bu hazırlık dönemi hiç bitmemektedir (Arnett, 2000, s. 477). Kiley (1983) de beliren yetişkinlik kavramından önce Peter Pan Sendromu'nu ortaya koymuş ve büyüme korkusundan bahsetmiştir. Peter Pan Sendromu, 30'lu yaşlardan sonra da devam eden, kişinin ruh sağlığını da tehdit eden psikolojik bir olgudur (Kiley, 1983, s. 15). Büyüme korkusu ise beliren yetişkinlik döneminin yaş aralığında bulunmayan, 25 yaşından büyük ve herhangi bir ruhsal bozukluğu olmayan kişilerin kendilerini hala bir yetişkin olarak tanımlayamaması sonucunda ortaya çıkan durumdur. Bu kişiler evlenmek, çocuk sahibi olmak, bir işte çalışmak için acele etmemektedirler (Arnett, 2000). Arnett’in (2000) beliren yetişkinlik için tanımlamış olduğu özellikler ile Kiley’in (1983, s. 26) Peter Pan Sendromu için tanımladığı özellikler karşılaştırıldığı zaman, arada kalmışlık ile istikrarsılık; sorumsuzluk ile kendine odaklanma; sosyal iktidarsızlık ile sonsuz olanaklar özellikleri birbiriyle örtüşmektedir. Büyüme korkusu ise sosyal-duygusal yalnıllık, romantik ilişkiyi sürdürmede zorlanma, evlenmeye karşı olumsuz tutumlar, bağımsız yaşama hazırlık ve sorumluluğu içselleştirmede zorlanma alt boyutlarıyla ön plana çıkmaktadır (Ateş ve Özden-Yıldırım, 2018).

Kiley' in (1983) öne sürdüğü Peter Pan Sendromu, ruh sağlı̆̆ını da tehdit eden psikolojik bir olgu olarak tanımlanmakta, fakat Dünya Sağlık Örgütü tarafindan henüz psikolojik bir rahatsızlık olarak kabul edilmemektedir. Büyüme korkusu ise herhangi bir ruhsal bozukluktan kaynaklanmamaktadır fakat eşlik eden psikolojik belirtiler olabileceği düşünülmektedir.

Çalışmada veri toplamak amacıyla kullanılan Kısa Semptom Envanteri'nin tespit ettiği psikolojik rahatsizlıklar; depresyon, somatizasyon, hostilite, anksiyete ve olumsuz benliktir. Depresyonda görülen belirtiler, çökkün duygudurum, enerji azlığı ve ilginin ya da alınan zevkin kaybı, konsantrasyon azlığ1, değersizlik düşünceleri, suçluluk duyguları, karamsarlık, kendine zarar verme ya da intihar düşünceleri, uyku düzeninde bozulma, iştah değişiklikleri ve libido azalmasıdır. Ayrıca sosyal ve mesleki işlevde bozulma da görülebilmektedir (Amerikan Psikiyatri Birliği [APA], 2014, s. 96). Diğer bir psikolojik rahatsızlık olarak ele alınan somatizasyon, Lipowski (1988, s. 1359) tarafindan kişinin fiziksel bulgularla açıklanamayan bedensel şikayetlerinin ve belirtilerinin olmasını içeren, aynı zamanda kişinin çok sayıda tıbbi yardım arama davranışı gösterdiği bir bozukluk olarak tanımlanmaktadır. Hostilite, öfke ve düşmanlık anlamına gelerek, kişinin gözünde diğerlerinin değer kaybetmesi, diğer kişilerin suçlu olmalarını umma, başkalarının incinme veya zarar görme deneyimlerine şahitlik isteği” olarak tanımlanmaktadır (Smith, 1994). Anksiyete ise kayg1 veya bunaltı olarak da adlandırılmaktadır (Karamustafalıoğlu ve Yumrukçay, 2011, s. 69). Anksiyetenin belirtileri arasında, çarpıntı, nefes almada zorluk, hızlı hızlı nefes alma, ellerde ve ayaklarda titreme, aşırı terleme, sıkıntı, heyecan, aniden çok kötü bir şey olacakmış hissi ve korkusu yer almaktadır. Kişinin işlevselliğini düşüren, sıklıkla titreme, çarpıntı, ağız kuruluğu, kas gerginliği gibi fiziksel belirtilerin de eşlik ettiği anksiyete durumları patolojik olarak değerlendirilmektedir (Karamustafalıoğlu ve Akpınar, 2010). Kısa Semptom Envanteri'nin belirttiği bir diğer psikolojik belirti olan olumsuz benlik, bireyin kendini başkalarıyla kıyasladığında yetersizlik ve küçüklük düşüncelerine kapılarak kendini başarısız, yetersiz ve değersiz görme gibi belirtiler yaşaması anlamına gelmektedir (Düzgün, 2003, s. 152).

Bu çalışmada da büyüme korkusu ile psikolojik belirtiler arasındaki ilişki incelenerek büyüme korkusu kavramı, bağımsız yaşama hazırlık ve sorumluluğu içselleştirmede zorlanma, evlenmeye karşı olumsuz tutum, sosyal-duygusal yalnızlık, romantik ilişkiyi sürdürmede zorlanma alt boyutları kapsamında daha detaylı ele alınmıştır. Bu amaç doğrultusunda aşağıda belirtilen araştırma soruları ele alınmıştır:

1. Büyüme korkusu ile psikolojik belirtiler arasında bir ilişki var mıdır?

2. Büyüme Korkusu'nun alt boyutu olan bağımsız yaşama hazırlık ve sorumluluğu içselleştirmede zorlanma, evlenmeye karşı olumsuz tutumlar, sosyal-duygusal yalnızlık ve romantik ilişkiyi sürdürmede zorlanma ile psikolojik belirtiler arasında bir ilişki var mıdır?

3. Psikolojik belirtilerin büyüme korkusunu yordayıcı rolü nedir?

4. Büyüme korkusu düzeyi cinsiyete göre farkll11k göstermekte midir?

5. 18-35 yaş arasında öğrenci veya çalışmayan kişiler ile çalısan kişilerin psikolojik belirti düzeyleri farklılaşmakta mıdır? 


\section{Yöntem}

Araştırmanın bu bölümünde çalışmada kullanılan Demografik Bilgi Formu, Kısa Semptom Envanteri ve Büyüme Korkusu Ölçeği’nden oluşan veri toplama araçlarına yönelik bilgiler verilmiştir.

\section{Evren - Örneklem}

$\mathrm{Bu}$ araştırmanın çalışma grubu, seçkisiz atama ile seçilmiş, çalışmaya katılmayı gönüllü olarak kabul etmiş 18-35 yaş aralığında bulunan, İstanbul'da yaşayan, 201 kadın ve 199 erkek olmak üzere toplam 400 kişiden oluşmaktadır. Katılımcıların demografik özelliklerine ait frekans ve yüzde değerleri Tablo 1 ve 2'de sunulmuştur.

Tablo 1. Cinsiyet Değişkeni için Frekans ve Yüzde Değerleri

\begin{tabular}{lcc}
\hline Cinsiyet & $f$ & $\%$ \\
\hline Kadn & 201 & 50.3 \\
Erkek & 199 & 49.8 \\
\hline
\end{tabular}

Tablo 1'e göre katılımciların \% 50.3’ü kadın, \% 49.8’i erkektir.

Tablo 2. Katıllmollarn Calşsma Durumu ile İlgili Frekans ve Yüzde Değerleri

\begin{tabular}{|c|c|c|}
\hline Çalişma Durumu & $f$ & $\%$ \\
\hline $\begin{array}{l}\text { Öğrenci/çalışmıyor } \\
\text { Calısıvor }\end{array}$ & $\begin{array}{l}210 \\
190\end{array}$ & $\begin{array}{l}52.5 \\
47.5\end{array}$ \\
\hline
\end{tabular}

Tablo 2'ye göre katılımcıların \% 52,5’i halen öğrencidir ve/veya bir işte çalışmamaktadır, \% 47,5’i ise çalışmaktadır.

\section{Veri Toplama Araçları}

Demografike Bilgi Formu. Araştırmacılar tarafindan hazırlanan demografik bilgi formunda, katılımcıların cinsiyeti, yaşı, çalışma durumu gibi sorular yer almaktadır.

Kısa Semptom Envanteri (KSE). Kısa Semptom Envanteri (KSE) kişilerde görülen psikolojik belirtileri tanımlamak üzere geliştirilmiş bir semptom tarama ölçeğidir. KSE'nin orijinal formu olan SCL-90, Derogatis (1979) tarafindan geliştirilmiştir. SCL-90 kısaltılarak 53 maddeye indirilmiş ve kısa formu oluşturulmuştur. Ölçek likert tipidir ve tüm maddeler $0-4$ arası derecelendirilmektedir $(0=$ hiç, $4=$ ileri derecede). Ölçeğin orijinal formu, 9 alt boyuttan oluşmaktadır. Bunlar; somatizasyon, obsesif-kompülsif bozukluk, kişilerarası duyarlılık, depresyon, anksiyete, hostilite, fobik anksiyete, paranoid düşünceler ve psikotizmdir (Şahin, Durak ve Uğurtaş, 2002).

Türkçe geçerlilik ve güvenilirlik çalışmaları Şahin ve Durak (1994) tarafından yapıllmıştır. Ölçeğin anksiyete, depresyon, olumsuz benlik, somatizasyon ve hostilite olmak üzere beş faktörden oluştuğu görülmektedir. KSE" nin iç tutarlılık katsayıları .70 ile .88 arasında değişmektedir (Şahin, Durak ve Uğurtaş, 2002). Bu çalışmada ölçeğin iç tutarlılık katsayısı .72 ile .76 arasında değişmiştir.

Büyüme Korkusu Ölçeği. Büyüme Korkusu Ölçeği, 18-35 yaş arasındaki kişilerin normal gelişim süreçleri içinde büyümek ve yetişkin olmakla ilgili korkularını ölçmek amacıyla Ateş ve Özden-Yıldırım (2018) tarafindan geliştirilmiştir. Ölçek, cevapların "Kesinlikle Katılıyorum (5)", "Katıliyorum (4)", "Kararsızım (3)", "Katılmıyorum (2)" ve "Kesinlikle Katılmıyorum (1)" şeklinde 5'li likert tipi bir ölçek şeklinde düzenlenmiştir. Toplam 733 kişi ile yürütülen çalışmada, 14 madde ve Sosyal-Duygusal Yalnızlık, Romantik İlişkileri Sürdürmede Zorlanma, Evlenmeye Karşı Olumsuz Tutumlar, Bağımsız Yaşama Hazırlık ve Sorumluluğu İçselleştirmede Zorlanma olarak 4 faktörden oluşan bir yapı elde edilmiştir. Ölçeğin tümü için elde edilen iç tutarll1ık katsayısı .75 olarak bulunmuştur (Ateş ve Özden-Yıldırım, 2018). Bu çalışmada ölçeğin iç tutarlılık katsayısı .76 olarak saptanmıştır.

\section{Verilerin Analizi}

Araştırmaya katılmak için gönüllü olan kişilere, kendilerini değerlendirmeleri üzere öz bildirim anketleri uygulanmıştır. Verilerin analizi SPSS 21.0 paket programında yapılmıştır. Verilerin analizinde Pearson Korelasyon Analizi ve Bağımsız Gruplar t-Testi kullanılmıştır. Tüm bu analizler için $\mathrm{p}<.05$ sonuçları istatistiksel olarak anlamlı kabul edilmiştir.

\section{Bulgular}


Çalışmanın bu bölümünde araştırma bulgularına yer verilmiştir. Araştırma değişkenlerine ait betimleyici bilgiler Tablo 3'te sunulmuştur.

Tablo 3. Araştırma Değzsskenlerine ait Ortalamalar ve Standart Sapmalar $(N=400)$

\begin{tabular}{|c|c|c|c|c|}
\hline & $\min$ & $\max$ & $\bar{X}$ & ss \\
\hline Anksiyete & 0 & 43 & 13.10 & 8.89 \\
\hline Depresyon & 0 & 48 & 15.49 & 9.46 \\
\hline Olumsuz Benlik & 0 & 40 & 12.28 & 8.08 \\
\hline Somatizasyon & 0 & 30 & 6.84 & 6.02 \\
\hline Hostilite & 0 & 27 & 9.79 & 5.29 \\
\hline Büyüme Korkusu Toplam & 14 & 58 & 34.19 & 8.33 \\
\hline Bağımsız Yaşama Hazırlık ve Sorumluluğu İçselleştirmede Zorlanma & 3 & 15 & 7.74 & 2.58 \\
\hline Evliliğe Karşı Olumsuz Tutum & 3 & 15 & 7.72 & 3.19 \\
\hline Romantik İlişkiyi Sürdürmede Zorlanma & 5 & 23 & 11.52 & 4.18 \\
\hline Sosyal Duygusal Yalnızlık & 3 & 15 & 7.21 & 2.54 \\
\hline
\end{tabular}

Büyüme korkusu toplam puanı ve alt boyutları ile psikolojik belirtiler arasındaki ilişkiye yönelik Pearson Korelasyon Analizi sonuçları Tablo 4'te sunulmuştur.

Tablo 4. Büyüme Korkusu ile Psikolojik Belirtiler Arasındaki İlişkiye Dair Pearson Korelasyon Analiz̨i Sonuclar $(N=400)$

\begin{tabular}{|c|c|c|c|c|c|c|c|c|c|c|}
\hline & 1 & 2 & 3 & 4 & 5 & 6 & 7 & 8 & 9 & 10 \\
\hline 1. Anksiyete & 1 & $.717 * *$ & $.721 * *$ & $.684^{* *}$ & $.647 * *$ & $.305^{* *}$ & $.200^{* *}$ & $.125^{*}$ & $.213^{* *}$ & $.290^{* *}$ \\
\hline 2. Depresyon & $.717 * *$ & 1 & $.730^{* *}$ & $.674^{* *}$ & $.640 * *$ & $.326^{* *}$ & $.188^{* *}$ & $.111^{*}$ & $.245^{* *}$ & $.336^{* *}$ \\
\hline 3. Olumsuz Benlik & $.721 * *$ & $.730 * *$ & 1 & $.577 * *$ & $.620 * *$ & $.278^{* *}$ & $.194^{* *}$ & .054 & $.183^{* *}$ & $.345^{* *}$ \\
\hline 4. Somatizasyon & $.684 * *$ & $.674 * *$ & $.577 * *$ & 1 & $.543^{* *}$ & $.236^{* *}$ & $.158^{* *}$ & .083 & $.138^{* *}$ & $.285^{* *}$ \\
\hline 5. Hostilite & $.647 * *$ & $.640 * *$ & $.620 * *$ & $.543^{* *}$ & 1 & $.257 * *$ & $.271 * *$ & .068 & $.164^{* *}$ & $.210^{* *}$ \\
\hline $\begin{array}{l}\text { 6. Büyüme Korkusu } \\
\text { Toplam }\end{array}$ & $.305^{* *}$ & $.326^{* *}$ & $.278^{* *}$ & $.236^{* *}$ & $.257^{* *}$ & 1 & $.611^{* *}$ & $.677 * *$ & $.825^{* *}$ & $.451^{* *}$ \\
\hline $\begin{array}{l}\text { 7. Bağımsız Yaşama } \\
\text { Hazırlık ve } \\
\text { Sorumluluğu } \\
\text { İçselleştirmede Zorlanma }\end{array}$ & $.200 * *$ & $.188^{* *}$ & $.194 * *$ & $.158 * *$ & $.271 * *$ & $.611^{* *}$ & 1 & $.229 * *$ & $.366^{* *}$ & .097 \\
\hline $\begin{array}{l}\text { 8. Evliliğe Karşı Olumsuz } \\
\text { Tutum }\end{array}$ & $.125^{*}$ & $.111 *$ & .054 & .083 & .068 & $.677^{* *}$ & $.229 * *$ & 1 & $.404^{* *}$ & .067 \\
\hline $\begin{array}{l}\text { 9. Romantik İlişkiyi } \\
\text { Sürdürmede Zorlanma }\end{array}$ & $.213^{* *}$ & $.245^{* *}$ & $.183^{* *}$ & $.138^{* *}$ & $.164 * *$ & $.825^{* *}$ & $.366^{* *}$ & $.404 * *$ & 1 & $.181^{* *}$ \\
\hline $\begin{array}{l}\text { 10. Sosyal Duygusal } \\
\text { Yalnızlık }\end{array}$ & $.290 * *$ & $.336^{* *}$ & $.345^{* *}$ & $.285^{* *}$ & $.210 * *$ & $.451^{* *}$ & .097 & .067 & $.181^{* *}$ & 1 \\
\hline
\end{tabular}

$* * \mathrm{p}<.01 * \mathrm{p}<.05$

Tablo 4'te görüldüğü üzere, büyüme korkusu ile psikolojik belirtilerden anksiyete $(\mathrm{r}=.305, \mathrm{p}<.01)$, depresyon $(\mathrm{r}=.326, \mathrm{p}<.01)$, olumsuz benlik $(\mathrm{r}=.278, \mathrm{p}<.01)$, somatizasyon $(\mathrm{r}=.326, \mathrm{p}<.01)$ ve hostilite $(\mathrm{r}=.257, \mathrm{p}<.01)$ arasında pozitif yönde anlamlı bir ilişki vardır. 18-35 yaş arası kişilerde anksiyete, depresyon, olumsuz benlik,somatizasyon ve hostilite düzeyleri arttıkça büyüme korkusu da artmaktadır.

Büyüme Korkusu Ölçeği'nin alt boyutları ile psikolojik belirtiler arasındaki ilişki incelendiği zaman bağımsız yaşama hazırlık ve sorumluluğu içselleştirmede zorlanmayı belirten alt boyutu ile anksiyete $(\mathrm{r}=.200, \mathrm{p}<.01)$, depresyon $(\mathrm{r}=.188, \mathrm{p}<.01)$, olumsuz benlik $(\mathrm{r}=.194, \mathrm{p}<.01)$, somatizasyon $(\mathrm{r}=.158$, $\mathrm{p}<.01)$ ve hostilite $(\mathrm{r}=.271, \mathrm{p}<.01)$ arasında pozitif yönde anlamlı bir ilişki vardır. Büyüme Korkusu Ölçeği'nin evliliğe karşı olumsuz tutum alt boyutu ile anksiyete $(\mathrm{r}=.125, \mathrm{p}<.05)$ ve depresyon $(\mathrm{r}=.111$, $\mathrm{p}<.05)$ arasında pozitif yönde anlamlı bir ilişki vardır. Evliliğe karşı olumsuz tutum alt boyutu ile olumsuz benlik, somatizasyon ve hostilite arasında ise anlamlı bir ilişki bulunmamıştır. Romantik ilişkiyi sürdürmede zorlanma alt boyutu ile anksiyete $(\mathrm{r}=.213, \mathrm{p}<.01)$, depresyon $(\mathrm{r}=.245, \mathrm{p}<.01)$, olumsuz benlik $(\mathrm{r}=.183$, $\mathrm{p}<.01)$, somatizasyon $(\mathrm{r}=.138, \mathrm{p}<.01)$ ve hostilite $(\mathrm{r}=.164, \mathrm{p}<.01)$ arasında pozitif yönde anlamlı bir ilişki vardır. Sosyal duygusal yalnızlık ile anksiyete $(\mathrm{r}=.290, \mathrm{p}<.01)$, depresyon $(\mathrm{r}=.336, \mathrm{p}<.01)$, olumsuz benlik $(\mathrm{r}=.345, \mathrm{p}<.01)$, somatizasyon $(\mathrm{r}=.285, \mathrm{p}<.01)$ ve hostilite $(\mathrm{r}=.210, \mathrm{p}<.01)$ arasinda da pozitif yönde anlamlı bir ilişki vardır. Buna göre 18-35 yaş arası kişilerde anksiyete, depresyon, olumsuz benlik, somatizasyon ve hostilite düzeyleri arttıkça bağımsız yaşama hazırlık ve sorumluluğu içselleştirmede 
zorlanma, romantik ilişkiyi sürdürmede zorlanma ve sosyal duygusal yalnızlık düzeylerinde de artış olmaktadır. Evliliğe karşı olumsuz tutum ise sadece anksiyete ve depresyonla ilişkili bulunmuştur. Kişilerde anksiyete ve depresyon düzeyleri arttıkça evliliğe karşı olumsuz tutum sergileme düzeyleri de artmaktadır.

Büyüme korkusunu yordayan psikolojik belirtileri belirlemek amacıyla yapılan hiyerarşik regresyon analizi sonuçları Tablo 5'te sunulmuştur.

Tablo 5. Büyüme Korkusunun Yordayuclarna İlişkin Hiyerarşik Regresyon Analiz̧i Sonuçlar

\begin{tabular}{|c|c|c|c|c|c|c|c|c|c|c|}
\hline & Yordayicilar & $B$ & $\begin{array}{l}\text { Std. } \\
\text { Hata } \\
\end{array}$ & $\beta$ & $t$ & $R$ & $R 2$ & $\begin{array}{c}\text { Düzeltilmis } \\
\text { R2 } \\
\end{array}$ & $F$ & $P$ \\
\hline \multirow[t]{2}{*}{ Model 1} & Sabit & 30.442 & .708 & & 43.002 & .305 & .093 & .091 & 40.817 & .000 \\
\hline & Anksiyete & .286 & .045 & .305 & 6.389 & & & & & .000 \\
\hline \multirow[t]{3}{*}{ Model 2} & Sabit & 29.376 & .772 & & 38.028 & .341 & .117 & .112 & 26.196 & .000 \\
\hline & Anksiyete & .138 & .063 & .147 & 2.171 & & & & & .031 \\
\hline & Depresyon & .194 & .060 & .220 & 3.255 & & & & & .001 \\
\hline \multirow[t]{4}{*}{ Model 3} & Sabit & 29.329 & .784 & & 37.413 & .342 & .117 & .110 & 17.470 & .000 \\
\hline & Anksiyete & .127 & .070 & .136 & 1.824 & & & & & .069 \\
\hline & $\begin{array}{l}\text { Depresyon } \\
\text { Olumsuz }\end{array}$ & .183 & .067 & .208 & 2.758 & & & & & .006 \\
\hline & Benlik & .028 & .078 & .027 & .361 & & & & & .718 \\
\hline \multirow[t]{5}{*}{ Model 4} & Sabit & 29.308 & .787 & & 37.261 & .342 & .117 & .108 & 13.113 & .000 \\
\hline & Anksiyete & .138 & .075 & .147 & 1.843 & & & & & .066 \\
\hline & $\begin{array}{l}\text { Depresyon } \\
\text { Olumsuz }\end{array}$ & .192 & .070 & .219 & 2.733 & & & & & .007 \\
\hline & Benlik & .029 & .078 & .028 & .364 & & & & & .716 \\
\hline & Somatizasyon & -.038 & .096 & -.027 & -.394 & & & & & .694 \\
\hline \multirow[t]{6}{*}{ Model 5} & Sabit & 29.095 & .868 & & 33.528 & .343 & .118 & .107 & 10.541 & .000 \\
\hline & Anksiyete & .128 & .077 & .136 & 1.662 & & & & & .097 \\
\hline & $\begin{array}{l}\text { Depresyon } \\
\text { Olumsuz }\end{array}$ & .184 & .072 & .209 & 2.554 & & & & & .011 \\
\hline & Benlik & .021 & .080 & .020 & .259 & & & & & .796 \\
\hline & Somatizasyon & -.042 & .097 & -.030 & -.433 & & & & & .665 \\
\hline & Hostilite & .061 & .105 & .039 & .583 & & & & & .560 \\
\hline
\end{tabular}

Tablo 5’te de görüldüğü üzere büyüme korkusunu yordadığ1 varsayılan psikolojik belirtileri saptamak amacıyla hiyerarşik regresyon analizi yapılmıştır. İlk adımda modele sadece anksiyete sokulmuştur. İkinci adımda anksiyete ve depresyon, üçüncü adımda anksiyete, depresyon ve olumsuz benlik, dördüncü adımda anksiyete, depresyon, olumsuz benlik ve somatizasyon, beşinci ve son adımda ise modele anksiyete, depresyon, olumsuz benlik, somatizasyon ve hostilite sokulmuştur. Yapılan regresyon analizi sonucuna göre ilk iki model büyüme korkusunu anlamlı düzeyde yordamıştır. Buna göre anksiyete, büyüme korkusundaki varyansın \% 9, 1'ini açıklamıştır $(\beta=.31, \mathrm{p}<.01)$. İkinci adımda modele eklenen depresyon ile anskiyetenin büyüme korkusunu yordama düzeyi $\% 11^{\prime} \operatorname{dir}(\beta=.22, \mathrm{p}<.01)$. Psikolojik belirtilerden olumsuz benlik, somatizasyon ve hostilitenin ise büyüme korkusunu yordayıc1 rolü bulunmamaktadır.

Büyüme korkusu düzeylerinin cinsiyete göre karşılaştırılması için yapılan Bağımsız Gruplar t-testi sonuçlar1 Tablo 6'da sunulmuştur.

Tablo 6. Kadın ve Erkeeklerin Büyüme Korkusu Dų̈̌ylerinin Karşılaștrılması için Yapılan Bağımsız, Gruplar t-Testi Sonuclar

\begin{tabular}{lllllll}
\hline Grup & $N$ & $\overline{\mathrm{X}}$ & $s s$ & $t$ & $s d$ & $p$ \\
\hline
\end{tabular}




\begin{tabular}{llllllll} 
Kadin & 201 & 34.08 & 8.43 & -.24 & 398 & .81 \\
Erkek & 199 & 34.29 & 8.26 & & & \\
\hline
\end{tabular}

Tablo 6'ya göre, kadın ve erkeklerin büyüme korkusu düzeyleri arasında anlamlı bir farklılık bulunmamıştır. Psikolojik belirtiler açısından incelendiğinde de kadın ve erkekler arasında yine anlamlı bir farkl11ı saptanmamıştır.

Katıllımcıların iş durumuna göre psikolojik belirtileri incelendiği zaman sadece olumsuz benlikle ilgili belirtileri açısından öğrenci olma ve/veya çalı̧mama ya da çalışma durumuna göre aralarında anlamlı farklılaşma olduğu saptanmıştır. Katılımcıların iş durumuna göre olumsuz benlikle ilgili belirtilerinin karşılaştırılması için yapılan Bağımsız t-Testi sonuçları Tablo 7'de sunulmuştur.

Tablo 7. Katıllmollarn Ișs Durumuna Göre Olumsuz Benlikle Ilgili Belirtilerinin Karşılaştırlması için Bağğmsı . Gruplar t-Testi Sonuclar

\begin{tabular}{lcccccc}
\hline Grup & $\boldsymbol{N}$ & $\overline{\mathrm{X}}$ & $\boldsymbol{s s}$ & $\boldsymbol{t}$ & $\boldsymbol{s} \boldsymbol{d}$ & $\boldsymbol{p}$ \\
\hline Öğrenci/çalı̧miyor & 210 & 1.09 & .72 & 2.1 & 397 & .03 \\
Çalışıor & 190 & .95 & .61 & & & \\
\hline
\end{tabular}

$\mathrm{p}<.05$

Tablo 7’ye göre, öğrenci ve/veya çalışmayan katılımcılar ile çalışan katılımcıların olumsuz benlikle ilgili belirtileri arasında anlamlı bir fark vardır. Öğrenci ve/veya çalışmayan katılımcıların olumsuz benlikle ilgili belirtileri çalışan katılımcılara göre anlamlı düzeyde daha yüksektir $(\mathrm{t}=2.1, \mathrm{p}<.05)$.

\section{Tartışma, Sonuç ve Öneriler}

18-35 yaş arasında 400 kişi ile yapılan bu çalışmada büyüme korkusu ve büyüme korkusunun alt boyutlan ile psikolojik belirtiler arasındaki ilişkinin incelenmesi ve bu ilişkiler doğrultusunda psikolojik belirtilerin büyüme korkusunu yordayıcı rolünün incelenmesi amaçlanmıştır. Bu temel amaç doğrultusunda yapılan analizler sonucunda büyüme korkusu ile psikolojik belirtilerden anksiyete, depresyon, olumsuz benlik, somatizasyon ve hostilite arasında pozitif yönde anlamlı ilişki bulunmuştur. Bu bulguya göre 18-35 yaş arası kişilerde anksiyete, depresyon, olumsuz benlik, somatizasyon ve hostilite düzeyleri arttıkça büyüme korkusu da artmaktadır.

18-35 yaş arası kişilerde anksiyete, depresyon, olumsuz benlik, somatizasyon ve hostilite düzeyleri arttıkça bağımsız yaşama hazırlık ve sorumluluğu içselleştirmede zorlanma, romantik ilişkiyi sürdürmede zorlanma ve sosyal duygusal yalnızlık düzeylerinde de artış olmaktadır. Evliliğe karşı olumsuz tutum ise sadece anksiyete ve depresyonla ilișkili bulunmuştur. Bu kişilerde anksiyete ve depresyon düzeyleri arttıkça evliliğe karşı olumsuz tutum sergileme düzeyleri de artmaktadır. Literatür incelendiğinde Levinson (1978) da 17-33 yaş arası dönemde kişilerin aşk, iş ve stabil yaşam yapısı kurmakla ilgili istikrarsızlıklar yaşadığını vurgulamıştır. Benzer şekilde Arnett (2000) de beliren yetişkinlik dönemi olarak tanımladığı dönemde kişilerin evlenmek, çocuk sahibi olmak, iş sahibi olmak gibi konularda acele etmediklerini, bu dönemin bir hazırlık dönemi olduğunu ama bazı kişilerde de bu hazırlık döneminin hiç bitmediğini belirtmiştir. $\mathrm{Bu}$ durumda kendini bir türlü yetişkin yaşamına hazır hissedememektedir, yetişkinliğin gerektirdiği sorumluluklardan kaçmakta ya da sadece onay görmek için sosyal gereklilikleri yerine getirmektedir. Tam olarak yetişkin rolüne giremeyen birey, "bana vaat edilen eğlenceyi ne zaman bulacağım" sorusunu kendine sormakta fakat bunun sonucunda da depresyon ve ümitsizlik yaşamaktadır (Ates ve Özden-Yıldırım, 2018, s.161). Atak (2009) da yaptığı çalışmada beliren yetişkinlikte yalnızlık ile nörotizm arasında pozitif yönde, dışadönüklük ve yumuşakbaşl1lık arasında ise negatif yönde anlamlı ilişki olduğunu belirtmiştir. Bu çalş̧mada da özellikle anksiyete ve depresyonun büyüme korkusunu yordayıcı rollerinin bulunması da Atak'ın (2009) çalışması ile paralellik göstermektedir. Kişilerde anksiyete ve depresyon düzeyleri yükseldikça yalnızlaşmakta, kendi dünyalarına kapanmakta, geleceğe yönelik sorumluluk gerektiren faaliyetlerden kaçınmaktadırlar.

Literatür incelendiğinde Kiley (1983) "Peter Pan Sendromu" adı altında tanımladığı büyüme korkusu yaşayan kişilerin erkekler olduğunu ifade etmiştir. Ancak Arnett'in (2000) "Beliren Yetişkinlik" kavramı her iki cinsiyeti de kapsamaktadır. Bu sebeple bu çalısmada kadınların ve erkeklerin büyüme korkusu düzeyleri arasında anlamlı bir farklıık olup olmadığı da incelenmiştir. Çalışmanın sonuçlarına göre kadınlar ve 
erkekler arasında büyüme korkusu açısından istatistiksel olarak anlamlı bir farklılık bulunmamıştır. Araştırma bulguları, Arnett'in (2000) tanımladığı beliren yetişkinlik kavramında olduğu gibi büyüme korkusunun iki cinsiyeti de kapsadığını desteklemektedir. Buna ek olarak psikolojik belirtiler açısından da kadın ve erkekler arasında anlamlı bir farklılık saptanmamıştır.

Katılımcıların çalışıp çalışmama durumuna göre psikolojik belirtileri incelendiği zaman sadece olumsuz benlikle ilgili belirtileri açısından aralarında anlamlı farklılık olduğu saptanmıştır. Çalışmanın bulgularnna göre öğrenci ve/veya çalışmayan kişilerin olumsuz benlikle ilgili belirtileri çalışan kişilere göre daha yüksektir. Burada da kişilerin ruhsal durumları üzerinde özellikle bir işte çalışıyor olmanın kendilerine verdiği üretkenlik duygusunun yarattığ olumlu etkileşimin araştırma bulgusuyla ilişkili olduğu düşünülmektedir. Çalışmanın örneklem grubunu da oluşturan 18-35 yaş arası kişiler, yakınlığa karşı yalıtılmışlık ve üretkenliğe karşı durgunluk dönemlerini de içermektedir (Erikson, 1968). Yakınlığa karşı yalıtılmışlık döneminde kişi, yakın ilişkiler kurma, aile kurma, üreme, topluma fayda sağlama gibi hedeflere sahiptir, böylece yalnızlıktan da uzaklaşır. Yakın ilişkiler kuramayan birey yalnızlığa sürüklenir, yetersizlik hisseder, insanlardan uzaklaşır. Sorumluluk almaktan kaçınmaya başlar, bunların başında da evlenmeyi erteleme gelir. Üretkenliğe karşı durgunluk döneminde kişi nasıl bir yaşam sürdürmüş olduğunu sorgular, verimli ve üretken bir yaşam sürdürmüş olma beklentisindedir. Kendine verimli ve üretken bir yaşam sürüp sürmediğini soran birey eğer olumlu bir şekilde bu soruyu cevaplayamiyorsa o zaman durgunlaşabilir, kendisi bir şeyler üretmektense başkalarının onun için çalışmasını isteyebilir, bu da kişinin bencilleşmesine de sebep olabilmektedir.

Araştırmadan elde edilen bulgulara göre 18-35 yaş arasındaki kişilerde psikolojik rahatsızlıklarla büyüme korkusu ilişkili bulunurken bunlardan sadece anksiyete ve depresyon sebebiyle büyüme korkusu geliştirdikleri saptanmıstır. Bu durumun etkenlerinden en önemli sebep olarak büyüme korkusu olan kişilerin hayatta sorumluluk almaktan kaçınmaları, bunun sonucunda da aslında kendilerini de tatmin edecek bir yaşam sürmemelerinin olduğu varsayılmaktadır. Anksiyete özellikle kişilerin sosyal ilişkilerini etkileyen bir rahatsızlıktır, yaşanan yoğun kaygılar kişileri asosyal olmaya itebilmektedir (Şahin, Aydın ve Sarı, 2012). Bununla paralel olarak duygusal yakınlık kurmaktan kaçınan kişiler aile bağları kurmaktan da uzaklaşmaktadırlar (Jackson ve Kirkpatrick, 2007). Literatür ile paralel olarak bu çalışmada da anksiyete ve depresyon, 18-35 yaş arasındaki kişilerin büyüme korkusunun alt boyutlanından romantik ilişkiyi sürdürmede zorlanmalarına ve sosyal duygusal yalnızlık duygularını yoğun olarak yaşamalarına sebep olmaktadır. Bu çalışma da literatür bulgularını destekler nitelikte Anksiyete ile depresyon kimi zaman içiçe de geçebilmektedir, Çuhadaroğlu (1993) ergenlerle yaptı̆̆ bir çalısmada anksiyete arttıkça depresif belirtilerin ortaya çıktığını ve klinik tablonun anksiyete bozukluğundan depresyona doğru değişebildiğini belirtmiştir.

Büyüme korkusu özgün ve yeni bir konu olduğu için ilgili çalışma sayısı çok kısıtlıdır bu sebeple bu çalışma, büyüme korkusu kavramının daha detaylı anlaşılması ve konuyla ilgili gelecekteki çalışmalara da kaynak oluşturması bakımından önem taşımaktadır. Son yıllarda özellikle 18-35 yaş arası popülasyonda kendini yetişkin olarak tanımlayamayan, yetişkin sorumluluklarını almaktan kaçınan genç bir kitle bulunmaktadır, bu kişilerin daha iyi anlaşılması, büyüme korkusunun altında yatan ya da ilişkili olabilecek durumların saptanabilmesi için konuyla ilgili çalısmaların artması gerekmektedir. Özellikle büyüme korkusunun farklı kültürlerde nasıl yaşandığı ve algılandığına dair kültürlerarası çalısmaların yapılması da alana katk1 sağlayacaktır.

\section{Kaynakça}

Amerikan Psikiyatri Birliği (2014). Rubsal bozukluklarn tanısal ve sayımsal elkitabı (DSM-5) (Çev. E. Köroğlu) (5. Baskı). Ankara: HYB Yayıncilik.

Arnett, J. J. (2000). Emerging adulthood: A theory of development from the late teens through the twenties. American Psychologist, 55(5), 469-480.

Arnett, J. J. (2004). Emerging adulthood: The winding road from the late teens through the twenties. New York: Oxford University Press.

Atak, H. (2009). Beliren yetişkinlikte beş büyük kişilik özelliği ve yalnızlık. X. Ulusal Psikolojik Damısma ve Rebberlik Kongresi, 21-23 Ekim 2009, Çukurova Üniversitesi, Adana.

Ateş, N. ve Özden-Yıldırım, M. S. (2018). Büyüme korkusu ölçeği’nin (BKÖ) geliştirilmesi: Geçerlilik ve güvenirlik çalş̧ması. Mehmet Akif Ersoy Üniversitesi Sosyal Bilimler Enstitiusï Dergisi, 10(24), 158-175. doi: 10.20875/makusobed.380022.

Çuhadaroğlu, F. (1993). Adolesanlarda depresyon ve anksiyetenin birlikte görülmesi: Gözden geçirme. Türk Psikiyatri Dergisi, 4(3), 183-188.

Derogatis, L. R. (1979). Symptom checklist-90-revised (SCL-90-R). Lyndhurst, NJ: NCS Pearson. 
Düzgün, Ş. (2003). Öğrencilerin psikolojik belirtileri ile ana-baba tutumları arasındaki ilişkiler. Atatürk Üniversitesi Sosyal Bilimler Enstitüsü Dergisi, 2(1-2), 149-162.

Erikson, E. H. (1968). Identity: Youth and crisis. New York: W.W. Norton \& Company, Inc.

Jackson, J. J., Kirkpatrick, L. A. (2007). The structure and measurement of human mating strategies: To-wards a multidimensional model of sociosexuality. Evolution Human Behavior, 28, 382-391.

Kiley, D. (1983). The Peter Pan syndrome: Men who have never grown up. New York: Dodd Mead.

Karamustafalıŏlu, O. ve Akpınar, A. (2010). Anksiyete bozuklukları. İçinde O. Karamustafalığlu (Edt.). Aile bekimleri için psikiyatri (ss. 71-88). İstanbul: MT Uluslararası Yayıncilık.

Karamustafalığlu, O. ve Yumrukçal, H. (2011). Depresyon ve anksiyete bozuklukları. Şişli Eftal Hastanesi Tip Bülteni, 45, 65-74.

Levinson, D. J. (1978). The seasons of a man's life. New York: Knopf.

Lipowski, Z. J. (1988). Somatization: The concept and its clinical application. The American Journal of Psychiatry, 145,1358-1368.

Smith, T. W. (1994). Concepts and methods in the study of anger, hostility, and health. In A. W. Siegman ve T. W. Smith (Eds.). Anger, hostility, and the heart (pp. 23-42). Hillsdale, NJ: Lawrence Erlbaum.

Şahin, M., Aydın, B. ve Sarı, S. V. (2012). Cyberbullying, cyber victimization and psychological symptoms : A study in adolescent. C.U. Faculty of Education Journal, 41(1), 53-59.

Şahin, N. H., Batıgün, A. D. ve Uğurtaş, S. (2002). Kısa semptom envanteri (KSE): Ergenler için kullanımının geçerlik, güvenilirlik ve faktör yapısı. Türk Psikiyatri Dergisi, 13(2), 125-135.

Şahin, N. H. ve Durak A. (1994). Kısa semptom envanteri: Türk gençleri için uyarlanması. Türk Psikoloji Dergisi, 9(31), 44-56.

\section{EXTENDED ABSTRACT}

In recent years it has been observed that individuals in the age group of 18-25, defined as young adults, have avoided many responsibilities expected from them. Although they have completed their adolescence, they do not yet identify themselves as adults. This period, which Arnett (2004) has described as an emerging adulthood, is also a period in which people seek to discover their abilities and limits. This period of identity search is like a pre-adult preparation period, but for some people, especially in recent years, this preparation period has never ended (Arnett, 2000). Kiley (1983), before the concept of emerging adulthood, revealed Peter Pan Syndrome and has mentioned about growth fear. Peter Pan Syndrome is a psychological phenomenon that continues after the ages of 30 and threatens the mental health of the person (Kiley, 1983). The growth fear is the case in the age range of the emerging adult period, when people who are older than age of 25 and do not have any mental disorder, cannot identify themselves as adults. These people do not rush to marry, have children or work in a job (Arnett, 2000). According to Arnett (2000), this period may also be a preparation period, but for some people this preparation period may never end. Arnett's (2000) features defined for emerging adulthood, and Kiley's (1983) features described for Peter Pan Syndrome, intermittence and instability; self-focus with irresponsibility; social impotence and infinite possibilities overlap. Growth fear comes to the fore with the subdimensions of social and emotional loneliness, difficulty in maintaining romantic relationship, negative attitudes against marriage, preparation for independent living and internalization of responsibility (Ates, \& Ozden Yildirim, 2018). The aim of this study was to investigate the relationship between growth fear and psychological symptoms. According to this purpose growth fear was tackled with its sub-dimensions; difficulty in preparation for independent living and internalization of responsibility, negative attitudes against marriage, social and emotional loneliness, difficulty in maintaining romantic relationship. Four problems were created for this purpose;

1. Is there a relationship between growth fear and psychological symptoms?

2. Is there a relationship between sub-dimensions of growth fear; difficulty in preparation for independent living and internalization of responsibility, negative attitudes against marriage, social and emotional loneliness, difficulty in maintaining romantic relationship and psychological symptoms?

3. Is there a predictive role of psychological symptoms on growth fear?

4. Is there a difference between growth fear levels of people according to gender?

5. Is there a difference between psychological symptoms' levels of people according to employment status?

The sample group of the study was consisted of a total of 400 adults (201 women and 199 men) aged 18-35, living in Istanbul. Demographical Information Form, Brief Symptom Inventory and Growth Fear 
Scale were used for data collection. Demographical Information Form, which was created by the researchers, was containing questions about the participants' gender, age, marital status, employment status. Brief Symptom Inventory (BSI) is a brief psychological self-report symptom scale. The Cronbach's Alpha internal consistency coefficient of the sub-scales is changed between .72 and .76. Growth Fear Scale measures fears of persons' about growing and being an adult, aged between 18-35 (Ates, \& Ozden Yildirim, 2018). For this study the Cronbach's Alpha internal consistency coefficient of the whole scale is .76. Data analysis was performed in SPSS 21.0 package program. Descriptive statistical analysis, Pearson Correlation Analysis and Independent Samples t-Test were used for data analysis. For all these statistical analyze, the significance level was accepted as .05 . The results of the study indicated that there was a positive significant relationship between growth fear and anxiety $(\mathrm{r}=.305, \mathrm{p}<.01)$, depression $(\mathrm{r}=.326$, $\mathrm{p}<.01)$, negative self $(\mathrm{r}=.278, \mathrm{p}<.01)$, somatization $(\mathrm{r}=.326, \mathrm{p}<.01)$ and hostility $(\mathrm{r}=.257, \mathrm{p}<.01)$. When the growth fear of people aged 18-35 increases, their anxiety, depression, negative self, somatization and hostility is also increases. When growth fear was examined through its sub-dimensions, there was a positive significant relationship between difficulty in preparation for independent living and internalization of responsibility and anxiety $(\mathrm{r}=.200, \mathrm{p}<.01)$, depression $(\mathrm{r}=.188, \mathrm{p}<.01)$, negative self $(\mathrm{r}=.194, \mathrm{p}<.01)$, somatization $(\mathrm{r}=.158, \mathrm{p}<.01)$ and hostility $(\mathrm{r}=.271, \mathrm{p}<.01)$. There was a positive significant relationship between difficulty in maintaining romantic relationship and anxiety $(\mathrm{r}=.213, \mathrm{p}<.01)$, depression $(\mathrm{r}=.245$, $\mathrm{p}<.01)$, negative self $(\mathrm{r}=.183, \mathrm{p}<.01)$, somatization $(\mathrm{r}=.138, \mathrm{p}<.01)$ and hostility $(\mathrm{r}=.164, \mathrm{p}<.01)$. There was a positive significant relationship between social and emotional loneliness and anxiety $(r=.290, p<.01)$, depression $(\mathrm{r}=.336, \mathrm{p}<.01)$, negative self $(\mathrm{r}=.345, \mathrm{p}<.01)$, somatization $(\mathrm{r}=.285, \mathrm{p}<.01)$ and hostility $(\mathrm{r}=.210, \mathrm{p}<.01)$. When the level of difficulty in preparation for independent living and internalization of responsibility of people aged between 18-35 increases, their anxiety, depression, negative self, somatization and hostility also increases. Negative attitudes against marriage was significantly positively related with only anxiety $(\mathrm{r}=.125, \mathrm{p}<.05)$ and depression $(\mathrm{r}=.111, \mathrm{p}<.05)$. When the negative attitudes of people, aged between 18-35, against marriage their anxiety and depression levels also increase. Only anxiety and depression have a predictive role on growth fear. The results of the hierarchical regression analysis demonstrated that anxiety was positively related with growth fear $(\beta=.31, \mathrm{p}<.01)$. Besides, when anxiety and depression were taken together in the regression analysis, the significance decreased $(\beta=.22, \mathrm{p}<.01)$ but it was still significant. There was no relationship found between women and men with regard to both growth fear and psychological symptoms. According to employment status of participants there was a significant difference only about their negative self-symptoms $(\mathrm{t}=2.1, \mathrm{p}<.05)$. According to the findings of the study, people do not develop growth fear because of psychological problems, but instead of psychological symptoms in people with fear of growth is thought to be more. The most important reason for this situation is that people who have growth fear avoid taking responsibility in life and as a result, they do not have a life to satisfy themselves. The current study is important with regard to understand growth fear detailed and to create resource for further studies. 